\title{
Esferas de Quitosana: Produção de Bases de Schiff
}

Giullia Perobelli* (Graduanda em Química na Universidade Federal do RN - UFRN); Nayara G. S. Cavalcante (Graduanda em Química na Universidade Federal do RN - UFRN); Ana Cristina F. de Brito Pontes (Prof. Ad. do IQ na Universidade Federal do RN - UFRN);

Daniel de Lima Pontes (Prof. Ad. do IQ na Universidade Federal do RN - UFRN);

*E-mail: giulliaperobelli@gmail.com

Resumo: A quitosana é um biopolímero derivado da quitina, o segundo polissacarídeo mais abundante na natureza, existente principalmente nas carapaças de crustáceos. Devido as suas diversas propriedades químicas e biológicas é frequente mente usado como objeto de pesquisa. A quitosana apresenta uma grande quantidade de grupos amino reativos em sua cadeia, possibilitando modificações químicas, como por exemplo a base de Schiff. As esferas de quitosana purificada, e de quitosana desacetilada, foram preparadas e modificadas para o estudo de novas aplicações. A reação de modificação de Base de Schiff é evidenciada pela presença do estiramento $\mathrm{C}=\mathrm{N}$, característico da função imina, pela presença das bandas referentes às ligações em compostos aromáticos pelo IV, e pelas bandas da vanilina presentes nos espectros eletrônicos. O estudo cinético realizado sobre a incorporação do complexo de cobre nas esferas mostra uma maior capacidade de adsorção para as esferas modificadas de quitosana desacetilada.

Pallavras-chave: quitosana; desacetilação; esferas; base de Schiff; adsorção.

\section{I ntrodução}

A quitina é o segundo polímero mais abundante na natureza, ocorrendo naturalmente no exoesqueleto de crustáceos, tais como camarão, lagosta e caranguejos. A quitosana é geralmente obtida pela $\mathrm{N}$-desacetilação da quitina em uma extensão variável, caracterizada pelo grau médio de desacetilação (GD), que representa a porcentagem de grupos $\mathrm{NH}_{2}$ livres. Quando o grau de desacetilação da quitina alcança em torno de 50\%, ela se torna solúvel em meio ácido e passa a ser chamada de quitosana.

A quitosana foi descoberta por Rouget em 1859, quando ele submetia a quitina a um tratamento com solução de hidróxido de potássio a quente. Entretanto, as primeiras pesquisas envolvendo-a só se iniciaram no século seguinte. (GOOSEN, 1997) Atualmente este polissacarídeo vem tomando um grande destaque nas pesquisas e aplicações, sendo considerado um dos materiais de maior potencial para o futuro próximo. Afirmação tomada com base na grande versatilidade de aplicações encontradas para este polímero e seus derivados. (NIFANT'EV, 1998)

Diferente da quitina a quitosana é solúvel em ácidos orgânicos, tais como ácido acético, ácido fórmico, ácido lático, assim como em ácidos inorgânicos, após longa agitação. A solubilização da quitosana ocorre pela protonação da função - $\mathrm{NH}_{2}$ sobre o carbono 2 da unidade de repetição D-glicosamina, portanto, o polissacarídeo é convertido em um polieletrólito em meio ácido. Sendo, então, um dos únicos polieletrólitos catiônicos encontrados na natureza, a quitosana possui propriedades excelentes. 
As possibilidades de modificação química da quitosana que se destacam são a $\mathrm{N}$ acetilação e a reação de Schiff, devido à grande quantidade de grupos amino reativos em sua cadeia. A reação de Schiff caracteriza-se pela formação de um grupo funcional onde existe ao menos uma ligação dupla de carbono-nitrogênio, onde o nitrogênio deve estar ligado a grupos arilas ou aquilas.

As bases de Schiff apresentam um papel importante na química de coordenação, pois formam complexos estáveis com vários metais de transição. De acordo com a facilidade de síntese, versatilidade de suas propriedades estéreas e eletrônicas, os complexos de base de Schiff com metais de transição têm despertado o interesse dos pesquisadores. Suas propriedades podem ser ajustadas e maximizadas de acordo com a escolha apropriada de aminas e substituintes na própria amina do composto carbonílico.

A vanilina ou 4-hidróxi-3-metoxibenzaldeído é um composto orgânico obtido tradicionalmente da vagem de uma orquídea tropical, mas devido aos custos elevados, hoje, é produzida de forma sintética para fins comerciais. Essa substância é um dos aromatizantes mais importantes, sendo utilizado em alimentos, bebidas, perfumes e fármacos. A vanilina possui propriedades antimicrobianas e antioxidantes

Diante do exposto, o objetivo do trabalho é obter uma base de Schiff biopolimérica a partir de esferas de quitosana e da vanilina com posterior incorporação de metais de transição.

\section{Experimental}

Os experimentos foram realizados no Laboratório de Química de Coordenação e Polímeros localizado na Universidade Federal do Rio Grande do Norte - UFRN. A quitosana usada nos experimentos é de origem comercial obtida através da desacetilação da quitina extraída exoesqueleto de crustáceos, como camarão, caranguejo e lagosta, comercializada pela empresa Polymar SA.

\subsection{Purificação da Quitosana Comercial}

A purificação da quitosana comercial foi conforme a metodologia Filho e Signini (2001), na forma de acetato. Na qual 1,5 g do polímero foi dissolvido em solução de acetado de sódio $(0,4 \mathrm{M})$ e ácido acético (2\%), sob agitação durante 24 horas. Após esse período a solução foi filtrada, precipitada em etanol, filtrada novamente e armazenada no dessecador.

\subsection{Desacetilação da Quitosana}

A desacetilação da quitosana seguiu, também, a metodologia de Filho e Signini (2001). Onde se preparou um banho de areia com a temperatura de $110^{\circ} \mathrm{C}$ constantes para deixar a 4,6 g de quitosana em solução de hidróxido de sódio (40\%). Depois de 2 horas a solução foi filtrada e lavou-se o pó obtido até a água de lavagem atingir um $\mathrm{pH}$ neutro. A quitosana desacetilada também foi purificada, e para essa purificação seguiu-se o mesmo método citado anteriormente.

\subsection{Determinação da Massa Molar Viscosimétrica e do Grau de Desacetilação}

Para determinações de viscosidade intrínseca, [ $\eta$ ], foi adotado o procedimento descrito por Signini e Campana Filho. Utilizando a equação (Mark-Houwink) abaixo é possível a determinação da massa molar viscosimétrica.

$$
[\eta]=\mathrm{K} \cdot \mathrm{MV} \alpha
$$


Em que, $[\eta]$ é a viscosidade intrínseca da solução, $K$ é uma constante característica do polímero e depende da temperatura e do solvente, $\alpha$ é a constante característica da geometria da molécula do polímero e Mv é a massa molecular viscosimétrica. O procedimento para encontrar o teor do grupamento acetil foi a metodologia relatada por Filho e Signini (1998).

\subsection{Obtenção das Esferas}

A metodologia empregada para obtenção de esferas de quitosana foi de coagulação em meio alcalino pelo gotejamento do polissacarídeo dissolvido em ácido, adaptando o método usado por Dias (2008). A quitosana, tanto a purificada como a desacetilada, foi solubilizada em solução de ácido acético (5\%) e deixada sob agitação durante 24 horas. A solução após esse intervalo adquiriu uma textura viscosa, e com auxílio de uma bureta foi gotejada em solução de hidróxido de sódio (2M) sob agitação.

\subsection{Formação da Base de Schiff}

A base de Schiff foi formada pelo contato das esferas de quitosana com uma solução de vanilina $(0,1 \% \mathrm{~m} / \mathrm{V})$ em metanol a $50{ }^{\circ} \mathrm{C}$ por 5 horas. Em seguida as esferas modificadas foram lavadas com etanol para retirar o excesso de vanilina e armazenadas em dessecador.

\subsection{Adsorção do Complexo de Cobre}

A adição do dicloro(1,10-fenantrolina)cobre(II) foi feita por meio de um acompanhamento cinético, onde as esferas modificadas ficaram em agitação com a solução do complexo de cobre. Durante o estudo foram retiradas alíquotas e obtidos os espectros eletrônicos na região ultravioleta visível.

\subsection{Espectroscopia na Região do I nfravermelho}

Para a obtenção de espectros na região do infravermelho foi preparada uma pastilha de $\mathrm{KBr}$ contendo cada umas das amostras do polímero (quitosana purificada, quitosana desacetilada e quitosana purificada modificada). $\mathrm{O}$ experimento foi realizado no equipamento Espectrofotômetro Shimadzu, modelo FTIR-8400S, localizado na Central Analítica do Instituto de Química da Universidade Federal do Rio Grande do Norte - UFRN.

\subsection{Espectroscopias na Região do Ultravioleta Visível}

Os espectros na região do ultravioleta visível foram obtidos em meio ácido utilizando o espectrofotômetro Uv-visível Ailent, modelo 8453, localizado no Laboratório de Química de Coordenação e Polímeros da Universidade Federal do Rio Grande do Norte - UFRN.

\section{Resultados e Discussões}

Segundo a literatura, a metodologia de purificação da quitosana está relacionada com suas propriedades e comportamentos distintos. A purificação da quitosana utilizada neste trabalho obteve um rendimento de $85 \%$. Os resultados de caracterização como grau de desacetilação (GD) e massa molar viscosimétrica $\left(\mathrm{M}_{\mathrm{v}}\right)$ da quitosana purificada $(\mathrm{QP})$ e desacetilada (QD) são apresentados na Tabela 1.

Tabela 1 - Valore médio do grau de desacetilação (GD) e da massa molar viscosimétrica $\left(\mathrm{M}_{\mathrm{v}}\right)$ da quitosana purificada e desacetilada. 


\begin{tabular}{c|c|c}
\hline & GD (\%) & $\mathbf{M}_{\mathbf{v}} \times \mathbf{1 0}^{4}(\mathbf{g} / \mathbf{m o l})$ \\
\hline QP & 52,1 & 4,1 \\
\hline QD & 89,9 & 2,4 \\
\hline
\end{tabular}

(Fonte: próprio autor)

As esferas de quitosana purificada e desacetilada foram analisadas antes e depois das modificações por espectroscopia na região do Infravermelho (Figura 1). A quitosana purificada apresenta uma banda na região $1881 \mathrm{~cm}^{-1}$, referente ao estiramento da ligação C-H. Esta banda também é observada na desacetilada em $2893 \mathrm{~cm}^{-1}$, porém apresenta uma menor intensidade, devido ao processo de desacetilação. Além da mudança de intensidade desta banda, também observou-se um aumento na intensidade da banda referente à ligação $\mathrm{N}-\mathrm{H}$, junto à diminuição da banda referente à ligação $\mathrm{C}=\mathrm{O}$. A alteração destas bandas deve-se pela maior presença de grupos $\mathrm{NH}_{2}$ livres, comprovando, assim, o aumento no grau de desacetilação da quitosana.

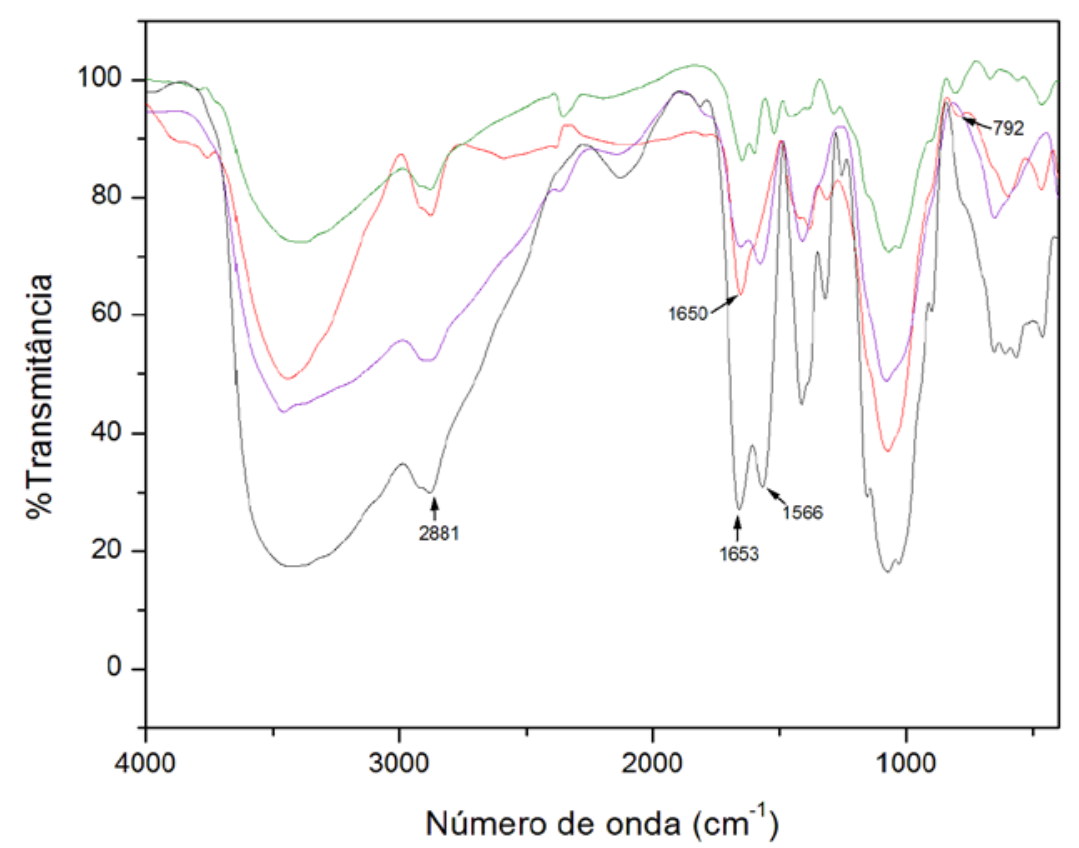

Figura 1 -Infravermelho em pastilha de $\mathrm{KBr}$ da quitosana purificada - (QP), das esferas modificadas de quitosana purificada - (BQP), da quitosana desacetilada - (QD) e das esferas modificadas de quitosana desacetilada - (BQD).

A figura 2 mostra a reação da vanilina com a quitosana, reação semelhante deve ocorrer com a quitosana desacetilada, entretanto em maior proporção, por conta do aumento dos grupamentos aminos.

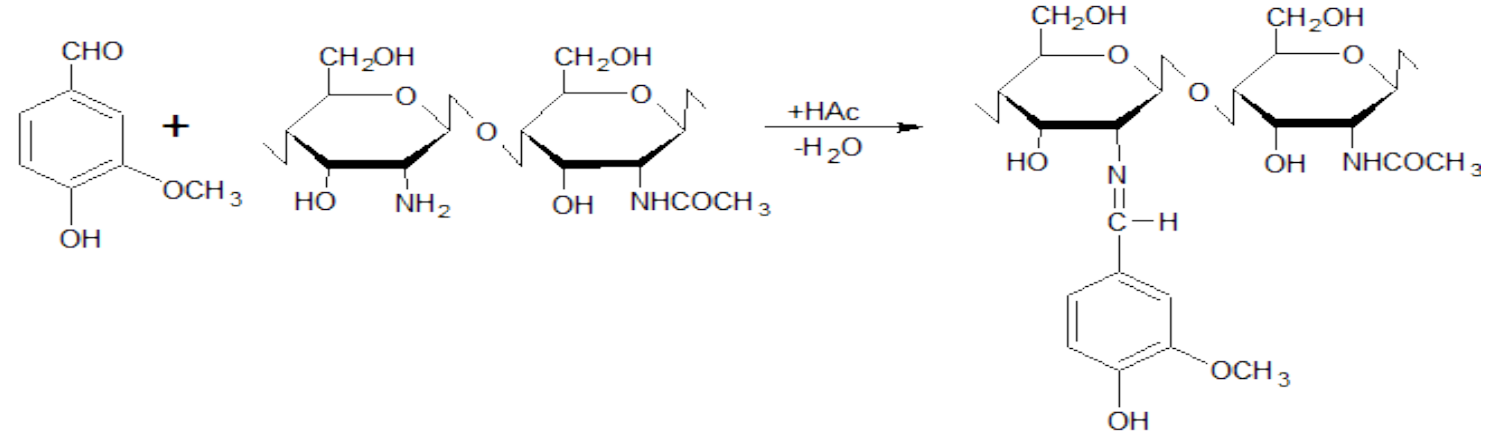

Figura 2 - Reação da vanilina com a quitosana para a obtenção de uma base de Schiff. 
Os espectros de IV das esferas modificadas de quitosana apresentaram bandas que evidenciam a formação da base de Schiff e a presença da vanilina na esfera (Figura 1). Como a banda referente ao estiramento causado pela ligação $C=C$, encontrada entre $1600-1590 \mathrm{~cm}^{-1}{ }^{1}$ nos espectros obtidos das esferas de quitosana purificada (BQP) e de quitosana desacetilada (BQD) modificadas com vanilina. Assim, como, a presença da banda referente ao estiramento $\mathrm{C}=\mathrm{N}$, principal evidência da formação da base de Schiff, na região de 1550-1570 $\mathrm{cm}^{-1}$. E bandas características de compostos aromáticos, como em 1300-1280 cm-1e em 790-810 cm-1 , referentes ao estiramento C-O e a deformação C-H, respectivamente.

O estudo espectroscópio na região do Ultravioleta Visível (Gráfico 3a) para a vanilina observa-se a presença de 4 bandas 204, 229, 279 e 309 nm, sendo esta última atribuída a transição $\mathrm{n}-\pi^{*}$ que envolve o grupo carbonila do aldeído substituído. Os espectros obtidos das esferas modificadas com vanilina apresentaram bandas idênticas ao da vanilina, tanto para a quitosana purificada, quanto para a quitosana desacetilada.

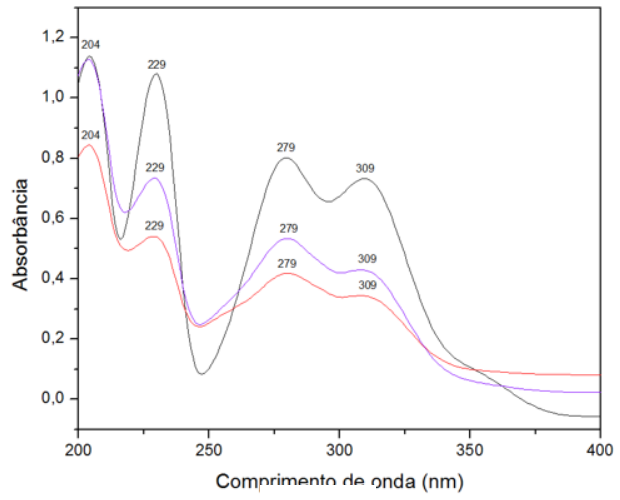

(a)

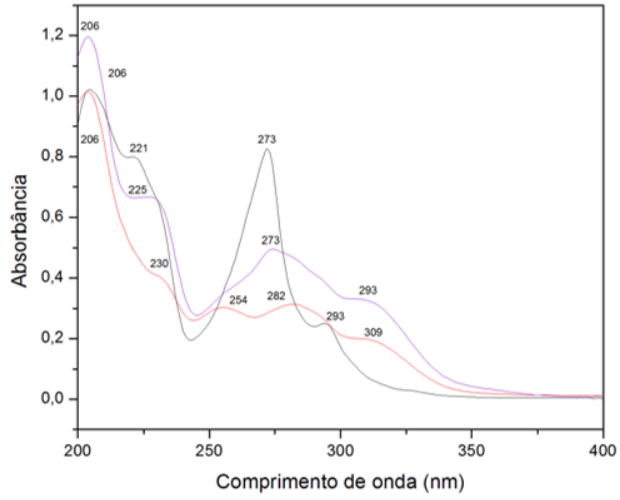

(b)

Figura 3 - (a) Espectros eletrônicos na região do Ultravioleta visível em meio ácido da —vanilina, —BQP e -BQD. (b) Espectros eletrônicos na região do Ultravioleta visível em meio ácido do — complexo, $\mathrm{BQP}$ e -BQD.

Para o complexo dicloro(1,10-fenantrolina)cobre(II), o espectro na região do Ultravioleta Visível, apresentou bandas em 206, 221, 273 e 293nm (Gráfico 3b). Nos espectros obtidos para as esferas modificadas após a adsorção do metal, verificou-se a ocorrência dos deslocamentos de algumas bandas e o aparecimento de uma nova banda no espectro da quitosana desacetilada. Esses deslocamentos indicam uma mudança na vizinhança, que pode ter sido provocada pela coordenação do complexo metálico a base de Schiff.

O estudo cinético de adsorção de complexo dicloro(1,10-fenantrolina)cobre(II) para esferas modificadas (Figura 4) mostrou-se que as esferas modificadas de quitosana purificada adsorveu o complexo de cobre durante 40 minutos, onde atingiu um equilíbrio até o fim do estudo cinético aos 240 minutos. Já as esferas modificadas de quitosana desacetilada continuaram a adsorver o complexo durante os 240 minutos observados, sem atingir um equilíbrio. Concluindo que as esferas de quitosana desacetilada possuem uma maior capacidade de adsorção. 


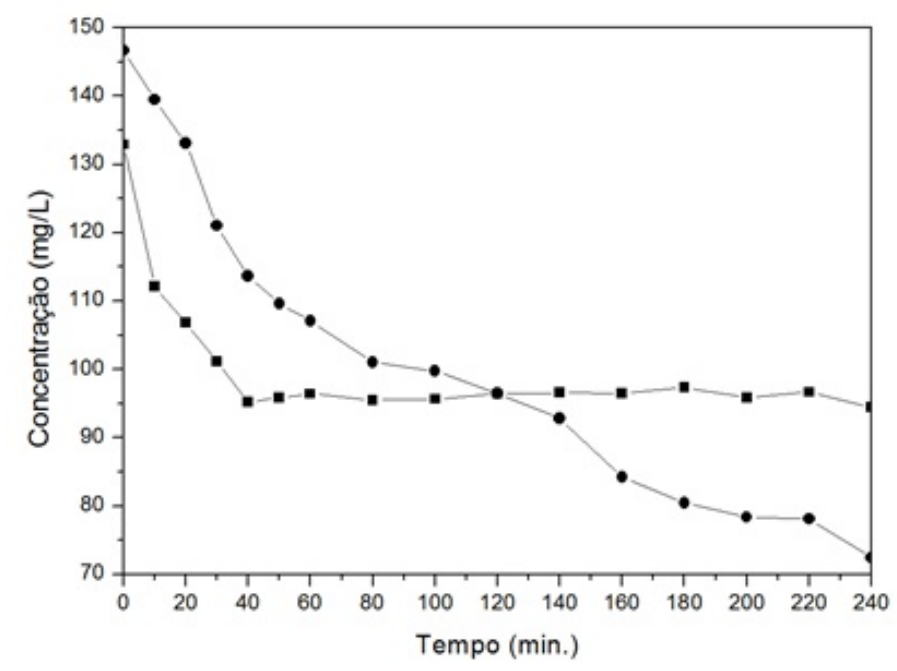

Figura 3 - Estudo cinético das esferas modificadas de quitosana purificada (BQP) (•) e estudo cinético das esferas modificadas de quitosana desacetilada (BQD) $(\bullet)$.

\section{Conclusões}

A desacetilação da quitosana é evidenciada pela presença da deformação em $1570 \mathrm{~cm}^{-1}$ referente à ligação N-H e diminuição do estiramento em $1660 \mathrm{~cm}^{-1}$ referente à ligação $\mathrm{C}=\mathrm{O}$, pelo Infravermelho. A reação de modificação de Base de Schiff foi caracterizada pela presença do estiramento $\mathrm{C}=\mathrm{N}$ em $1650 \mathrm{~cm}^{-1}$, característico da função imina e pela presença das bandas referentes às ligações $\mathrm{C}-\mathrm{O}$ e C-H em compostos aromáticos também pelo IV, e pelas bandas da vanilina presentes nos espectros eletrônicos. O estudo cinético realizado sobre a incorporação do complexo de cobre nas esferas mostra uma maior capacidade de adsorção para as esferas modificadas de quitosana desacetilada, que após os 240 minutos não continuaram adsorvendo o complexo. Enquanto as esferas modificadas de quitosana purificadas incorporaram o complexo apenas durando 40 minutos, quando atingiu um equilíbrio.

\section{Chitosan Beads: Production Schiff Bases}

Abstract: Chitosan is a biopolymer derived from chitin, the second most abundant polysaccharide in nature, existing primarily in the shells of crustaceans. Because of their different chemical and biological properties is often mind used as a research object. Chitosan has a large amount of reactive amino groups in their chain, allowing chemical modifications, such as the Schiff base. The beads of purified chitosan, and deacetylated chitosan were prepared and modified for the study of new applications. The reaction Schiff Base modification is evidenced by the presence of the $\mathrm{C}=\mathrm{C}$ stretching, characteristic of the imine function, the presence of the bands in aromatic compounds by IV and the bands vanillin present the electronic spectra. The kinetic study on the merger of the copper complex in the spheres shows a higher adsorption capacity for modified deacetylated chitosan beads.

Keywords: chitosan beads; deacetylation; Schiff bases; adsorption.

\section{Referências bibliográficas}


REKHA, S.; NAGASUNDARA, K.R. Complexes of the Schiff base derived from 4-aminophenyl benzimidazole and 2, 2'- dehydropyrollidene-N-aldehyde with Zn (II), Cd (II) and Hg (II) halides, Indian J. Chem., 54A: 2006.

RAMAN, N.; SELVAN, A.; SUDHARSAN, S. Metallation of ethylenediamine based Schiff base with biologically active $\mathrm{Cu}(\mathrm{II}), \mathrm{Ni}(\mathrm{II})$ and $\mathrm{Zn}(\mathrm{II})$ ions: synthesis, spectroscopic characterization, electrochemical behaviour, DNA binding, photonuclease activity and in vitro antimicrobial efficacy, Spectrochim. Acta, 79, 5: 2011.

GOLCU, A.; TUMER, M.; DEMIRELLI, H.; WHEATLEY, R.A. Cd(II) and Cu(II) complexes of polydentate Schiff base ligands: synthesis, characterization, properties and biological activity. Inorg. Chim. Acta, 358, 6: 2005.

AZIZ, A. A. A.; SALEM, A. N. M.; SAYED, M. A.; ABOALY, M. M.; MOL, J. Synthesis, structural characterization, thermal studies, catalytic efficiency and antimicrobial activity of some M (II) complexes with ONO tridentate Schiff base N-salicylidene-o-aminophenol (saphH 2), Struct., 1010: 2012.

JIANG, C.; MING, Z.; TAN, Q.; QIAN, D.; YOU, T., Asymmetric cyclopropanation catalyzed by a series of copper-(Schiff-base) complexes with two chiral centers, Enantiomer, 7, 6: 2002.

BORGOGNONI, C. F.; POLAKIEWICZ, B.; PITOMBO, R.N.M. Estabilidade de emulsões de DLimoneno em quitosana modificada, Ciênc. Tecnol. Aliment., 26, 32006.

GOY, R. C.; ASSIS, O. R. G.; CAMPANA-FILHO, S. P. Produção de Esferas de Quitosana: Meio para Interação com Metais em Fase Aquosa, Biotecnologia Ciência \& Desenvolvimento, 33: 2004

DIAS, F. S; QUEIROZ, D. C.; NASCIMENTO, R. F; LIMA, M. B. Um sistema simples para preparação de microesferas de quitosana. Química. Nova, 31, 1: 2008.

SIGNINI, R.; CAMPANA-FILHO, S. P. Características e propriedades de quitosanas purificadas nas formas neutra, acetato e cloridrato, Polímeros: Ciência e Tecnologia, 11: 2001.

SIGNINI, R.; CAMPANA-FILHO, S. P. Purificação e caracterização de quitosana commercial, Polímeros: Ciência e Tecnologia, 4: 1998.

GOOSEN, M.F.A. Applications of chitin and chitosan, Technomic. Lancaster: 1997.

NIFANT’EV, N. E.; CHERNETSKII, V.N. Mendeleev Chem. J. 1998.

GUO, Z.; XING, R.; LIU, S.; ZHONG, Z.; JI, X.; WANG, L.; LI, P. Antifungal properties of Schiff bases of chitosan, N-substituted chitosan and quaternized chitosan, Carbohydr. Res. 342, 10: 2007. 